\title{
In-vitro fertilization of preovulatory human eggs
}

\author{
A. Lopata, R. McMaster, J. C. McBain* and W. I. H. Johnston* \\ Department of Obstetrics and Gynaecology, and Department of Anatomy, \\ Monash University, and \\ *Reproductive Biology Unit, The Royal Women's Hospital, Melbourne, Australia
}

\begin{abstract}
Summary. Preovulatory eggs were aspirated from the ovaries of women $36-38 \mathrm{~h}$ after hCG and incubated with washed sperm suspensions for 3 or $6 \mathrm{~h} ; 5$ out of 9 eggs were fertilized. Sperm penetration into the ooplasm and decondensation of the male chromatin was observed by $3 \mathrm{~h}$, and an early pronucleate egg was found by $6 \mathrm{~h}$, suggesting that human spermatozoa may become capacitated in vitro in 3-4 h.
\end{abstract}

\section{Introduction}

Human eggs can be fertilized in vitro. Soupart \& Strong (1974) provided convincing morphological evidence of in-vitro fertilization by showing a sperm midpiece and tail in a pronucleate egg. They cultured eggs for $48 \mathrm{~h}$ before incubation with a sperm suspension for $24 \mathrm{~h}$ but did not examine shorter times of insemination. Edwards, Bavister \& Steptoe (1969) also used oocytes which had been matured in culture but studied earlier stages of sperm penetration: they found 3 eggs with spermatozoa in the perivitelline space by $7-7.5 \mathrm{~h}$, and one pronucleate egg by $11.5 \mathrm{~h}$ after insemination. In a subsequent report Bavister, Edwards \& Steptoe (1969) published photographs of stained whole-mount preparations showing a sperm tail in an early pronucleate egg examined $11-11.75 \mathrm{~h}$ after insemination in vitro.

There is therefore a lack of knowledge on the time required for the development of fertilizing capacity by ejaculated human spermatozoa and on the timing of sperm penetration into human eggs. The present experiments were conducted to examine sperm penetration into preovulatory human eggs at 3 and $6 \mathrm{~h}$ after insemination in vitro.

\section{Materials and Methods}

Preovulatory eggs were obtained from the ovaries of infertile patients at diagnostic laparoscopies, or at laparotomies for tubal surgery, usually performed on Days 11-15 of a regular 26-28-day menstrual cycle (onset of menstruation is Day 1). Eggs for in-vitro insemination were collected only from women who agreed to have an injection of 3000 i.u. hCG (Primogonyl: Schering) 36-38 h before the operation. At the time of surgery the largest, presumably preovulatory, follicles were aspirated separately in each ovary and one or two preovulatory eggs, readily identified by their massive cumulus, were obtained from about $40 \%$ of the women receiving hCG.

Eleven preovulatory eggs have been studied. Two were used for the preparation of meiotic chromosomes by the method of Tarkowski (1966). Both of these eggs were found to be at second meiotic metaphase. The remaining eggs were used to study the fertilization process; 4 were incubated under paraffin oil with a sperm suspension for $3 \mathrm{~h}$ and 5 for $6 \mathrm{~h}$. The Medium (S) in which the spermatozoa were suspended had the following composition (mM): $\mathrm{NaCl}, 99 \cdot 14 ; \mathrm{KCl}, 5 \cdot 36 ; \mathrm{CaCl}_{2}, 2 \cdot 72$; $\mathrm{MgCl}_{2}, 0.49$; sodium lactate, $9.98 ; \mathrm{NaH}_{2} \mathrm{PO}_{4}, 0.32$; glucose, 5.55 ; sodium pyruvate, $0.33 ; \mathrm{NaHCO}_{3}$, 30.95; it also contained $5 \mathrm{mg}$ bovine serum albumin (Calbiochem, grade A)/ml, $10 \mu \mathrm{g}$ phenol red $/ \mathrm{ml}$, and 100 i.u. penicillin $\mathrm{G} / \mathrm{ml}$. The osmolality of the medium was $285-295 \mathrm{mosmol} / \mathrm{kg}$ and the $\mathrm{pH}$ $7 \cdot 45-7 \cdot 55$.

The suspensions of spermatozoa used in each experiment were prepared from fresh ejaculates of 
the same fertile donor. Immediately after the semen had liquefied a $0.5 \mathrm{ml}$ sample was diluted in $3.0 \mathrm{ml}$ of the suspending medium (Medium S) and centrifuged at $200 \mathrm{~g}$ for $10 \mathrm{~min}$. The sperm pellet was resuspended in another $3.0 \mathrm{ml}$ Medium $S$ and centrifuged as before. The final sperm pellet was dispersed in a small volume of Medium $S$ to obtain a sperm concentration of $15 \times 10^{6}-25 \times 10^{6}$ cells per $\mathrm{ml}$. Approximately $0.5 \mathrm{ml}$ of this sperm suspension was placed under paraffin oil and incubated for $1.5 \mathrm{~h}$ in an atmosphere of $5 \% \mathrm{CO}_{2}$ in air at $37^{\circ} \mathrm{C}$. During this incubation period the preovulatory eggs were collected, washed in two separate droplets of Medium S, and transferred into $0.1 \mathrm{ml}$ Medium $S$ under paraffin oil. About $10 \mu$ of the suspension of preincubated spermatozoa, taken from near the surface of the suspension to obtain a high percentage of motile cells, were added to the droplet containing the egg and thoroughly mixed.

After incubation for 3 or $6 \mathrm{~h}$ in the sperm suspensions, the eggs were transferred directly into $5 \%$ glutaraldehyde in $0 \cdot 1 \mathrm{M}$-cacodylate buffer $(\mathrm{pH} 7 \cdot 4)$ and kept at $4{ }^{\circ} \mathrm{C}$ for $1 \mathrm{~h}$. They were postfixed in $2 \%$ osmium tetroxide in $0.1 \mathrm{M}$-cacodylate buffer, rapidly dehydrated in graded alcohol solutions and embedded in Epon. A Reichert OMU 3 Ultrotome was used to cut serial $1 \mu \mathrm{m}$ sections of the eggs. The sections were stained with $1 \%$ toluidine blue and examined with a Zeiss photomicroscope.

\section{Observations}

By $3 \mathrm{~h}$ after the start of the incubation with spermatozoa morphological evidence of fertilization was obtained in 3 out of the 4 eggs examined (Table 1). An ovum which contained all of the criteria of fertilization is illustrated in Pl. 1, Fig. 1: a swollen sperm head with its midpiece and flagellum were present within the vitellus. At the time of fixation the egg was extruding the second polar body into the perivitelline space; the polar body was still attached to the vitellus by a metaphase plate. A distinct

Table 1. Morphological criteria of fertilization found after incubation of human preovulatory eggs with spermatozoa for 3 or $6 \mathrm{~h}$

\begin{tabular}{|c|c|c|c|c|c|}
\hline $\begin{array}{c}\text { Incubation } \\
\text { time }\end{array}$ & Egg & $\begin{array}{l}\text { Sperm } \\
\text { components } \\
\text { in } \\
\text { vitellus }\end{array}$ & $\begin{array}{l}\text { Second polar } \\
\text { body extruding } \\
\text { or extruded }\end{array}$ & $\begin{array}{c}\text { Two } \\
\text { pronuclei }\end{array}$ & $\begin{array}{c}\text { Cortical } \\
\text { granules } \\
\text { in } \\
\text { ooplasm }\end{array}$ \\
\hline \multirow[t]{4}{*}{$3 \mathrm{~h}$} & 1 & $\begin{array}{l}\text { Head, } \\
\text { midpiece } \\
\text { and tail }\end{array}$ & Yes & No & Absent \\
\hline & 2 & Head & Yes & No & Absent \\
\hline & 3 & 一 $^{*}$ & Yes & No & Absent \\
\hline & 4 & None & No & No & Present \\
\hline \multirow[t]{5}{*}{$6 \mathrm{~h}$} & 1 & Tail & Yes & Yes & Absent \\
\hline & 2 & None & No & No & Present \\
\hline & 3 & None & No & No & Present \\
\hline & 4 & $\begin{array}{l}\text { Head and } \\
\text { midpiece }\end{array}$ & Yes & No & Absent \\
\hline & 5 & None & No & No & Present \\
\hline
\end{tabular}

* Several sections of this egg could not be examined.

\section{EXPLANATION OF PLATE 1}

Fig. 1. A $1 \mu \mathrm{m}$ section of a fertilized human egg fixed after $3 \mathrm{~h}$ of incubation with spermatozoa. The decondensing chromatin of the fertilizing sperm head (sp) and its midpiece (mp) can be seen within the ooplasm. $\times 785$.

Fig. 2. A section through an early pronucleate egg fixed after $6 \mathrm{~h}$ of incubation with spermatozoa. The female pronucleus ( $\mathrm{fn}$ ) is adjacent to the first and second polar bodies ( $\mathrm{pbl}$ and $\mathrm{pb2}$ ). $\times 630$.

Fig. 3. A section through a different level of the egg shown in Fig. 2, showing the male pronucleus (mn) and surrounding asymmetrically distributed cytoplasmic organelles. $\times 630$. 
PLATE 1
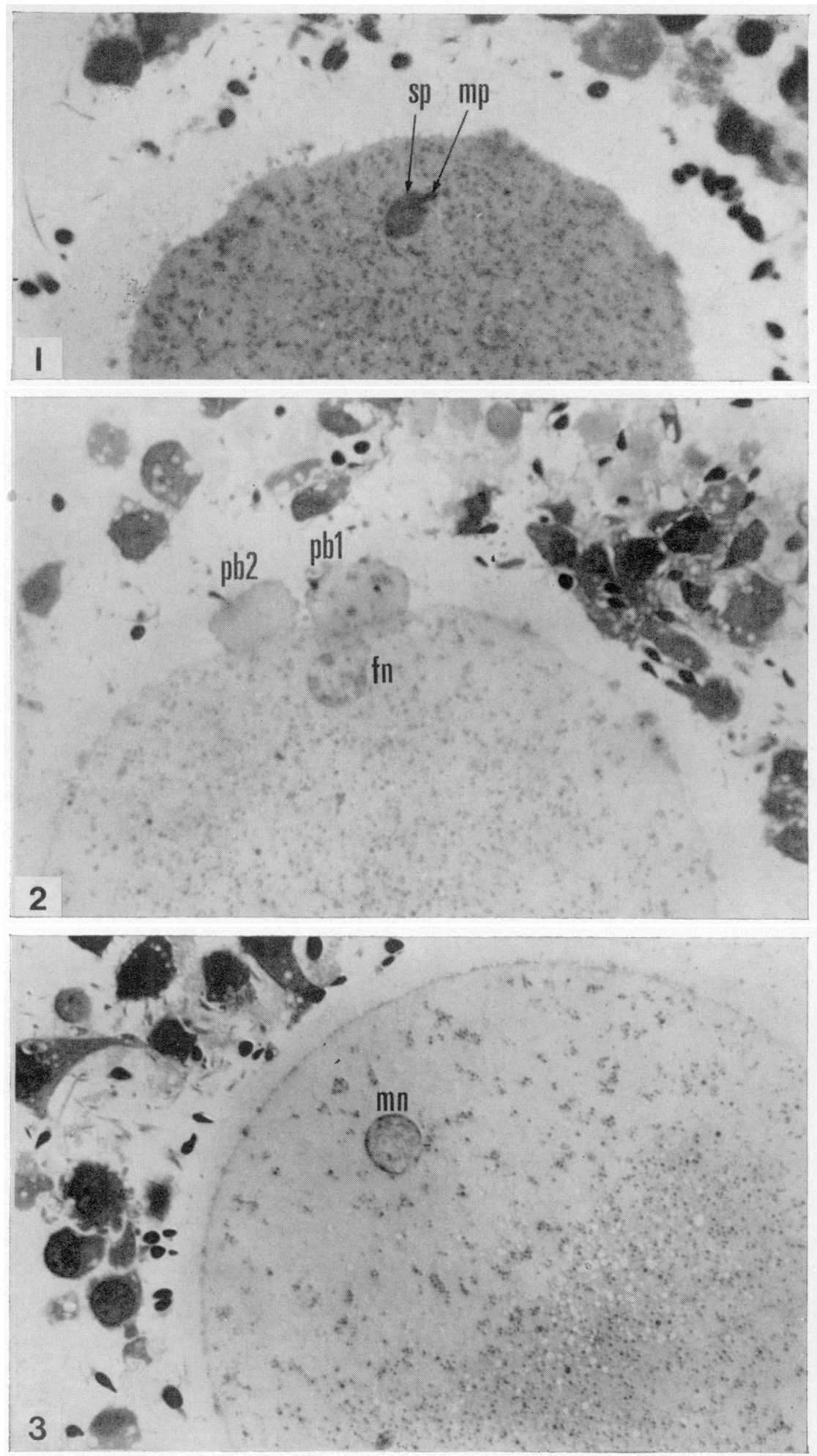
first polar body, containing cortical granules, chromosomes and other organelles, was located in an adjacent area of the perivitelline space. Cortical granules were missing from the sub-oolemmal region of the vitellus, suggesting that the cortical reaction had occurred.

Judging by the sequence of second polar body extrusion, one egg was at an earlier stage of fertilization and one appeared to be at a slightly more advanced stage than the ovum shown in Pl. 1, Fig. 1.

After $6 \mathrm{~h}$ of incubation, 2 eggs were fertilized, one of which had progressed to the early pronuclear stage of development (Table 1). The ovum shown in Pl. 1, Figs 2-3, contained all the accepted morphological parameters of fertilization. The first and second polar bodies had been extruded into the perivitelline space and were adjacent to one another. The female pronucleus (Pl. 1, Fig. 2) was situated at the periphery of the ooplasm close to the expelled second polar body. The male pronucleus (P1. 1, Fig. 3) was located deeper in the ooplasm, about $30-40 \mu \mathrm{m}$ from its female counterpart. The flagellum of the fertilizing spermatozoon was situated in the vicinity of the male pronucleus. The early pronuclei were about $10 \mu \mathrm{m}$ in diameter and had clumps of condensed chromatin on the inner surface of the pronuclear envelope. Nucleoli were not evident in the pronucleoplasm. Cortical granules were observed in the first polar body but had disappeared from the peripheral ooplasm.

\section{Discussion}

It may be concluded from the present studies that human preovulatory eggs undergo fertilization within $3 \mathrm{~h}$ of their insemination in vitro. The minimum time required for ejaculated human spermatozoa to acquire fertilizing capacity in vitro is unknown. It is clear, however, that in the present in-vitro system the time required for capacitation, passage of spermatozoa through the egg investments, and commencement of sperm chromatin decondensation within the vitellus was less than $5 \mathrm{~h}$. If attachment of a spermatozoon to the surface of the zona pellucida, or the commencement of sperm passage through the zona, are parameters which adequately differentiate capacitated or acrosome-reacted human spermatozoa from unreacted spermatozoa, shorter insemination intervals would define more precisely the time needed by human spermatozoa to acquire fertilizing ability.

There is no information on the capacitation of spermatozoa and the fertilization process in the human genital tract. In the non-human primate, the time sequence of fertilization in vivo was studied by Marston \& Kelly (1968). Epididymal spermatozoa were placed in the uteri of rhesus monkeys which had already ovulated and the eggs were recovered $6 \mathrm{~h}$ later: 3 out of 9 eggs were fertilized. One of these 3 eggs had developed to the pronuclear stage. Although the time required to attain this stage after fertilization in vivo is unknown, Seitz, Brackett \& Mastroianni (1973) have suggested that capacitation in the genital tract of the monkey is completed about $3-4 \mathrm{~h}$ after insemination. Since the present study has shown that fertilization of human eggs had occurred by $3 \mathrm{~h}$, and a pronucleate egg had developed by $6 \mathrm{~h}$ after insemination, the time required for the capacitation of human spermatozoa in vitro may be similar to, or shorter than, the time required for the capacitation of monkey spermatozoa in vivo.

This work was supported by a Ford Foundation Grant to the Department of Obstetrics and Gynaecology, Monash University. Technical assistance was provided by Mrs Margaret Patullo and Mrs Joan Clark.

\section{References}

Bavister, B.D., Edwards, R.G. \& Steptoe, P.C. (1969) Identification of the mid-piece and tail of the spermatozoon during fertilization of human eggs in vitro. $J$. Reprod. Fert. 20, 159-160.

EdWards, R.G., Bavister, B.D. \& StePtoe, P.C. (1969)
Early stages of fertilization in vitro of human oocytes matured in vitro. Nature Lond. 221, 632-635.

Marston, J.H. \& Kelly, W.A. (1968) Time relationships of spermatozoon penetration into the egg of the rhesus monkey. Nature, Lond. 217, 1073-1074. 
Settz, H.M., JR, BracketT, B.G. \& MAstroianNi, L., J़ (1973) Fertilization. In Human Reproduction, pp. 119-131. Eds E. S. E. Hafez \& T. N. Evans. Harper and Row, Hagerstown.

Soupart, P. \& STRONG, P.A. (1974) Ultrastructural observations on human oocytes fertilized in vitro. Fert.
Steril. 25, 11-44.

TARKowski, A.F. (1966) An air drying method for chromosome preparations from mouse eggs. Cytogenetics 5, $394-400$.

Received 16 August 1977 